\title{
Honeymoon not yet over for pharma-biotech deals
}

In early June, when SmithKline Beecham (SB, London) formed a research agreement with its long-time rival in antibacterial drugs, GlaxoWellcome (GW, London), to collaborate on the complete sequencing of a number of pathogenic bacteria, SB admitted that the collaboration was "unusual," and a direct result of the high cost of doing deals with biotechnology companies-genomics companies in particular. Two weeks after a World Health Organization (WHO, Geneva) declaration that drug-resistant bacteria numbers are reaching crisis proportions, and noting that the last new class of antibiotics was discovered in the mid-1970s, SB announced a new in-house initiative in genomics and drug discovery to focus on developing new antibiotics capable of fighting drug-resistant bacteria.

"The deal between SB and GW is not only unusual, it may be unprecedented," said a pharmaceutical and biotechnology analyst in London. Until now, most deals between two large pharmaceutical companies have been only for marketing, such as the recent deal between Pfizer (Southport, NC) and Warner Lambert (Morris Plains, NJ) for Atorvastatin, or the agreement between Merck (Whitehouse Station, NJ) and Johnson \& Johnson (New Brunswick, NJ) to market Pepcid-not for research and development of new drugs.

The current deal, which involves no exchange of cash, was made following discussions with a number of biotechnology companies, after which it became clear that the most cost-effective approach was to work with SB, said GW spokesperson Richard Sluder. "Both companies believed that by joining forces, we would be able to succeed in a shorter time and at a lower cost than had we worked independently or with biotechnology companies," he added. Doing deals with biotechnology companies until now has not been an issue, with both pharmaceutical companies maintaining numerous $R \& D$ collaborations.

"The cost of biotechnology deals have gone through the roof" says SB spokesperson Alan Chandler, and because of that the potential risk of sharing data for use in both companies' R\&D programs seems worthwhile. He admits, though, that "it is highly likely that there will be competition over bringing similar compounds to market at the same time resulting from [the] joint research."

So are biotechnology collaborations

Vicki Brower is a freelance writer working in New York. beginning to price themselves out of the market? If so, then, as the Wall Street Journal (June 7, 1996) noted, "Glaxo and SmithKline bear a major share of the blame. Both have raced to form a web of global research alliances in recent years, shelling out eyepopping sums to lock up promising partners"-most notably, the 1993 SB-Human Genome Sciences' (Rockville, MD) \$125 million agreement.

Most analysts, including Hambrecht \& Quist's (New York) Alex Zisson and Smith Barney's (New York) Toni Claudio believe that the deal is not a harbinger of a future of fewer biotechnology/pharmaceutical company deals and an increase in deals between pharmaceutical companies. Vector Securities (Deerfield, IL) analyst Peter Ginsburg noted no change in the number of deals between the first and second quarters of 1996, and Oppenheimer \& Co.'s (New York) Sharon Seiler believes that the numbers of pharmaceutical/biotechnology company deals have in fact increased over the past few months, with the dollar value still on the rise in spite of lagging biotechnology stock prices.

That pharmaceutical/biotechnology deals are still going strong can be seen in the Guilford (Baltimore, MD)-Rhone Poulenc Rorer (Collegeville, PA) $\$ 99.5$ million agreement in June for the Gliadel wafer treatment for brain cancer, and the Baxter (Deerfield, IL)-Inhale Therapeutics (Palo Alto, CA) $\$ 80$ million deal earlier this year. Seiler doesn't believe such deals have been overvalued. "Pharmaceutical companies are careful shoppers," she observed.

The number and value of recent biotechnology deals have more to do with a relative slowing of capital available, says Zisson. "Biotechnology strategic partnerships have an inverse relationship to how easy it is to raise money in capital markets." The past 16 months have seen a boom in initial public offerings (IPOs) and secondary financings, in which even small or very early-stage companies have been able to raise money; that trend is slowing down now, Zisson observes. "We are becoming more selective as the year goes on, and have begun turning down IPOs for companies that may have good technology but with products at a very early stage of development."

As well as a drop in total money raised by biotechnology companies from investors from $\$ 1.4875$ billion in May to $\$ 926.5 \mathrm{mil}$ lion in June, other recent signs of biotechnology stock weakness include Genzyme's (Cambridge, MA) cancellation of its planned convertible debt offering and postponement of Cell Therapeutics' (Seattle, WA) planned IPO for $\$ 38.5$ million. Zisson believes that the lower stock prices over the past few months are due to the fear of rising interest rates, "which is the key to going public." Even if cash is less plentiful, and stock prices fall, biotechnology deals will not wane, most agree.

Vicki Brower

\section{Pathogen patchwork could cultivate noncompliance}

Officials at the Centers for Disease Control and Prevention (CDC, Atlanta, GA) in midJune issued proposed rules for shipping and handling within the United States of infectious disease agents and toxins with a high potential for use by terrorists as biological warfare agents. Backed by stiff fines and imprisonment for serious infractions, the rules would apply broadly to investigators working at public and private institutions. Despite specific exemptions for research and clinical purposes, however, the proposals could well confuse companies and individuals who already deal with a patchwork of overlapping rules from federal bodies and private organizations.

The US Congress mandated CDC to issue new rules to help in implementing the Antiterrorism and Effective Death Penalty Act, which was signed into law this spring. That law arose in response to an incident in 1995 involving an individual who, allegedly for illicit purposes, obtained a sample of Yersinia pestis, the bacterium that causes bubonic plague, from the American Type Culture Collection (ATCC, Rockville, MD).

Although ATCC representatives cooperated with federal authorities to head off any serious ill consequences, that incident triggered a review of safety and security procedures pertaining to sales and other exchanges of infectious agents and related substances used in research, clinical, and other biomedical settings. In general, CDC officials say, the safety and security record for the sale and distribution of infectious agents and toxins is satisfactory.

Meanwhile, the proposed regulations contain several important, potentially bur- 